\title{
Degradabilidade ruminal in situ de vagens de faveira (Parkia platycephala Benth.) em diferentes tamanhos de partículas
}

[In situ ruminal degradability of faveira (Parkia platycephala Benth.) pods in different particle sizes]

\author{
A.A. Alves $^{1,6}$, R.O. Sales $^{2}$, J.N.M. Neiva ${ }^{3}$, A.N. Medeiros $^{4}$, A.P. Braga ${ }^{5}$, A.R. Azevedo ${ }^{2}$ \\ ${ }^{1}$ Departamento de Zootecnia - CCA-UFPI \\ Campus Agrícola da Socopo \\ 64049-550 - Teresina, PI \\ ${ }^{2}$ Departamento de Zootecnia - CCA-UFC - Fortaleza, CE \\ ${ }^{3}$ Departamento de Zootecnia - UFT - Araguaína, TO \\ ${ }^{4}$ Departamento de Zootecnia - CCA-UFPB - Areia, PB \\ ${ }^{5}$ Departamento de Zootecnia - ESAM - Mossoró, RN \\ ${ }^{6}$ Bolsista da CAPES
}

\begin{abstract}
RESUMO
Estimaram-se os parâmetros de degradação ruminal da matéria seca (MS) e da proteína bruta (PB) de vagens de faveira, trituradas em partículas de 2 e $5 \mathrm{~mm}$, pelo método do saco de náilon in situ em ovinos, nos tempos de incubação 3, 6, 12, 24, 48, 72 e 96 horas, e determinou-se a degradabilidade efetiva, considerando-se taxas de passagem 2, 5 e 8\%/h. A fração $a$ da MS e da PB foram 69,6 e 49,9\%, respectivamente, revelando elevada solubilidade da MS; a fração $b$ para MS e PB foi 24,7 e 43,9\%, indicando baixa degradação da MS in situ, com estabilização da degradação da MS às $72 \mathrm{~h}$ e da $\mathrm{PB}$ às $48 \mathrm{~h}$ de incubação. O tanino de vagens de faveira não se mostrou depressor da degradabilidade in situ da PB.
\end{abstract}

Palavras-chave: ruminante, tamanho de partícula, vagem de leguminosa, valor nutritivo

\begin{abstract}
Soluble (a) and potentially degradable (b) fractions and degradation rate of b fraction (c) of dry matter (DM) and crude protein (CP) of Parkia platycephala pods in particle sizes 2 and $5 \mathrm{~mm}$ were estimated by in situ nylon bag method in sheep. The times of incubation were 3, 6, 12, 24, 48, 72 and 96 hours, and the effective degradability (ED) was determined considering passage rates of 2, 5 and 8\%/h. The a fractions for DM and CP was 69.6 and 49.9\%, respectively, revealing elevated DM solubility: The b fractions for $D M$ and $C P$ was 24.7 and 43.9\%, denoting reduced DM in situ degradation. The stabilization of the DM and $C P$ degradation occurred at $72 \mathrm{~h}$ and $48 \mathrm{~h}$ after incubation, respectively. In situ degradability of constituents of $\mathrm{P}$. platycephala pods, in special CP, were not depressed for their tannin contents.
\end{abstract}

Keywords: ruminant, leguminous pod, particle size, nutritive value

\section{INTRODUÇÃO}

A faveira (Parkia platycephala Benth.) é uma leguminosa arbórea de ocorrência natural em áreas do cerrado brasileiro, onde suas vagens são muito utilizadas na suplementação alimentar de ruminantes. A partir dos dados de produção média de vagens de faveira, segundo Carvalho e Ramos (1983), e da densidade de até 40 plantas/ha em áreas de chapadas, segundo Nascimento et al. (1996), é possível estimar-se a produção anual de vagens em até $1.208 \mathrm{~kg} / \mathrm{ha}$.

Recebido em 20 de dezembro de 2005

Aceito em 2 de abril de 2007

*Autor para correspondência (corresponding author)

E-mail: arnaud@ufpi.br 
Apesar da disponibilidade de vagens e da importância para a suplementação de ruminantes em ecossistemas de pastagem de cerrado, tanto por consumo direto de vagens no campo quanto pelo fornecimento em suplementos após coleta, não há disponibilidade de dados de degradabilidade de nutrientes, particularmente da matéria seca e proteína.

A técnica de sacos de náilon no rúmen é útil para se determinar a degradabilidade de diferentes frações, como matéria seca (MS) e proteína bruta (PB), e comparar diferentes produtos, sendo considerada por Nocek (1997) como a mais utilizada para se avaliar a degradação protéica ruminal, devido à facilidade de padronização dessa técnica entre laboratórios. No entanto, segundo esse autor, a literatura não é convincente quanto ao efeito do tamanho da partícula sobre a taxa de digestão de concentrados e ingredientes ricos em proteína, sendo necessário considerar as características físicas dos alimentos. Assim, sugere-se que suplementos protéicos, como o farelo de soja e a farinha de peixe, e alguns subprodutos, como os farelos de trigo e de glúten de milho, deveriam ser moídos a $2 \mathrm{~mm}$, enquanto os grãos de cereais e subprodutos fibrosos, como a casca de soja e o resíduo de cervejaria, o feno e as forragens com MS acima de $60 \%$, deveriam ser moídos a $5 \mathrm{~mm}$.

Parece evidente que, à medida que o preparo da amostra imprima uma forma que mais se afaste daquela naturalmente imposta pelo animal, mais distante da realidade estarão os dados. Este fato torna-se mais importante quando se deseja caracterizar o alimento como ingrediente para formulação de rações (Andrade, 1994).

Devido à riqueza em carboidratos não fibrosos da vagem de faveira que, ao ser triturada em moinhos de malha reduzida, apresenta tendência à caramelização, a prática recomenda sua trituração a $5 \mathrm{~mm}$ para incluí-la em dietas e tornála disponível aos microrganismos do rúmen. Assim, a avaliação do tamanho da partícula indica maior aproximação das condições práticas, sendo importante manter relação com tamanhos de partículas convencionalmente adotados em experimentos in situ com o uso de peneiras de crivos de 2 a $2,5 \mathrm{~mm}$, segundo Andrade (1994).
O objetivo deste trabalho foi estimar parâmetros de degradação ruminal de vagens de faveira (Parkia platycephala Benth.) sob diferentes tamanhos de partículas.

\section{MATERIAL E MÉTODOS}

O experimento foi realizado para estimar parâmetros de degradação ruminal in situ da MS e PB de vagens de faveira (Parkia platycephala Benth.), em partículas de 2 e $5 \mathrm{~mm}$, tendo como alimento referência o feno de capim-Tifton 85 (Cynodon spp.), processado em partículas de $2 \mathrm{~mm}$, por constituir o volumoso da dieta dos ovinos durante o experimento, e pela existência de resultados na literatura que permitem aferir os dados obtidos.

As vagens de faveira foram coletadas no município de Piracuruca, Piauí, após maturação natural; o capim-Tifton 85, também utilizado como base para a dieta, foi fenado aos 45 dias da rebrota. Os dados da composição bromatológica de ambos são apresentados na Tab. 1 .

Tabela 1. Composição bromatológica do feno de capim-Tifton 85 (Cynodon spp.) e de vagens de faveira (Parkia platycephala Benth.)

\begin{tabular}{lcc}
\hline $\begin{array}{l}\text { Constituinte } \\
\text { (\% da MS) }\end{array}$ & $\begin{array}{c}\text { Feno de capim- } \\
\text { Tifton } 85\end{array}$ & $\begin{array}{c}\text { Vagens de } \\
\text { faveira }\end{array}$ \\
\hline Matéria seca (MS;\%) & 89,13 & 77,25 \\
Matéria orgânica & 92,03 & 97,37 \\
Proteína bruta & 9,14 & 11,18 \\
Extrato etéreo & 1,49 & 1,25 \\
Carboidratos totais & 75,80 & 79,44 \\
Carboidratos não fibrosos & 7,13 & 68,12 \\
Fibra em detergente neutro & 79,34 & 19,70 \\
Fibra em detergente ácido & 41,68 & 13,10 \\
Lignina em detergente ácido & 5,61 & 5,50 \\
Nitrogênio insolúvel em & 0,82 & 0,45 \\
detergente neutro & & \\
Nitrogênio insolúvel em & 0,19 & 0,17 \\
detergente ácido & & \\
Fenóis totais ${ }^{1}$ & - & 12,33 \\
Taninos totais ${ }^{1}$ & - & 10,79 \\
Taninos condensados & & \\
Nutrientes digestíveis totais ${ }^{3}$ & 59,83 & 72,51 \\
\hline${ }^{1}$ Equivalente ácido tânico; & ${ }^{2}$ Equivalente & leucocianidina; \\
${ }^{3}$ Segundo Alves et al. (2003). & &
\end{tabular}

Foram utilizados quatro carneiros adultos, castrados, mestiços da raça Santa-inês, com peso vivo inicial médio $49,1 \pm 7,6 \mathrm{~kg}$, alojados em baias individuais, providos de cânula ruminal e mantidos em sistema de alimentação com dieta para mantença com consumo na proporção de $1,9 \%$ do peso vivo, formulada segundo o NRC 
(Nutrient..., 1985), cuja composição centesimal e bromatológica está apresentada na Tab. 2 .

Tabela 2. Composição centesimal e bromatológica da dieta para mantença de ovinos, fornecida durante o ensaio de degradabilidade in situ ${ }^{1}$

\begin{tabular}{lc}
\hline Ingrediente/Constituinte & \% da dieta \\
\hline Composição percentual & 60,00 \\
\hline Feno de capim-Tifton 85 (Cynodon spp.) & 12,00 \\
Milho em grão & 20,00 \\
Vagens de faveira & 8,00 \\
Farelo de trigo & \\
Composição bromatológica & 86,56 \\
Matéria seca (\%) & $\%$ na matéria \\
& seca \\
Matéria mineral & 5,99 \\
Proténa bruta & 10,87 \\
Extrato etéreo & 2,53 \\
Fibra em detergente neutro & 50,74 \\
Fibra em detergente ácido & 26,99 \\
Nutrientes digestíveis totais ${ }^{2}$ & 65,04 \\
\hline Thormulada segundo o NRC (Nutrient..., 1985). \\
${ }^{2}$ Calculado a partir de dados obtidos por Alves et al. (2003) \\
para feno de capim-Tifton 85 e vagens de faveira e de \\
dados apresentados por Campos (1995) e pelo NRC \\
(Nutrient..., 2001) para milho em grão e farelo de trigo, \\
respectivamente.
\end{tabular}

Durante o período de incubação, a condição do ambiente ruminal foi monitorada, coletando-se $100 \mathrm{ml}$ de líquido ruminal (LR), por ocasião das incubações nos tempos 3, 24 e $72 \mathrm{~h}$ e determinado o $\mathrm{pH}$ do LR utilizando-se potenciômetro digital ${ }^{1}$ imediatamente após a coleta. Após filtração em quatro camadas de gaze, foram tomadas alíquotas de $40 \mathrm{ml}$ de $\mathrm{LR}$, acondicionadas em frascos âmbar vedados com tampa, fixadas com $1 \mathrm{ml}$ de $\mathrm{HCl}$ (1:1), e armazenadas em freezer de -5 a $-10^{\circ} \mathrm{C}$ para posterior determinação da concentração de nitrogênio amoniacal $\left(\mathrm{N}-\mathrm{NH}_{3}\right)$ pelo método descrito por Vieira (1980). Alíquotas de $50 \mathrm{ml}$ de LR foram acondicionadas em frascos âmbar tampados, com $10 \mathrm{ml}$ de solução ortofosfórica a $25 \%$, e armazenadas em freezer de -5 a $-10^{\circ} \mathrm{C}$, para posterior quantificação da concentração de ácidos graxos voláteis, por cromatografia de fase líquida de alta eficiência (HPLC), segundo Mathew et al. (1997).

As incubações in situ foram realizadas em sacos de náilon de $8 \times 12 \mathrm{~cm}$ e porosidade $50 \mu \mathrm{m}$, introduzindo-se $4 \mathrm{~g}$ de amostra por saco de náilon, segundo Sampaio (1994), de forma seqüenciada, iniciando-se pelo maior tempo de

${ }^{1}$ pHmetro SCHOTT Handylab1 incubação. Os sacos, em triplicata para obtenção de amostra suficiente para análises, foram incubados nos tempos de 3, 6, 12, 24, 48, 72 e $96 \mathrm{~h}$, suspensos por fío de náilon de $20 \mathrm{~cm} \mathrm{e}$ ancorados à porção ventral do rúmen por um peso de $75 \mathrm{~g}$. A fração prontamente solúvel foi determinada conforme procedimento descrito por Makkar (1999).

Os resíduos de degradação para cada tempo e alimento formaram uma amostra composta por animal, que depois de moída a $1 \mathrm{~mm}$ em moinho Willey, foi submetida à determinação dos teores de MS (método $\mathrm{n}^{\circ}$. 930.15) e PB pelo método Kjeldahl (método $n^{\circ}$. 920.39), segundo AOAC... (Official..., 1990).

Utilizando-se o resíduo insolúvel em detergente ácido, determinado pelo método $\mathrm{n}^{\circ} .973 .18$ (Official..., 1990), e em detergente neutro, de acordo com Van Soest et al. (1991), estimaramse os teores de nitrogênio insolúvel em detergente ácido (NIDA) e em detergente neutro (NIDN), pelo processo semimicro Kjeldahl (método $\mathrm{n}^{\circ}$. 984.13; Official..., 1990).

Também foram determinados os teores de matéria mineral (método $\mathrm{n}^{\circ}$. 942.05), visando à correção da FDN e FDA, de EE (método $\mathrm{n}^{\mathrm{o}}$. 920.39) e de lignina em detergente ácido (método $\mathrm{n}^{\mathrm{o}}$. 973.18), segundo AOAC... (Official..., 1990). Os carboidratos totais (CHOT) foram calculados segundo Sniffen et al. (1992), os carboidratos não fibrosos (CNF) segundo Hall (2000), e as estimativas de nutrientes digestíveis totais (NDT), a partir do sistema de Weiss et al. (1992), utilizando-se os dados de digestibilidade in vivo, obtidos por Alves et al. (2003).

A extração dos compostos fenólicos seguiu o método recomendado pela FAO (Quantification..., 2000), utilizando-se como solvente acetona aquosa (70:30; v/v); os conteúdos de fenóis totais e taninos totais foram analisados pelo método Folin Ciocalteu e o de taninos condensados pelo método descrito por Nozella (2001).

Os parâmetros de degradação in situ e a degradabilidade potencial foram estimados segundo o modelo proposto por Sampaio et al. (1995), a partir de simplificação do modelo de Ørskov e McDonald (1979). A degradabilidade 
efetiva (DE) foi calculada pela equação proposta por Ørskov e McDonald (1979).

Foram realizadas estatísticas descritivas para média, desvio padrão e coeficiente de variação, segundo o PROC MEANS do SAS (User's..., 2000); os parâmetros $a, b$ e $c$, e as curvas de degradação in situ dos princípios nutritivos foram obtidos segundo a equação exponencial proposta por Ørskov e McDonald (1979) e determinados utilizando-se o método interativo de Gauss-Newton do PROC NLIN do SAS (User's..., 2000).

\section{RESULTADOS E DISCUSSÃO}

$\mathrm{O} \mathrm{pH}$ do líquido ruminal foi $6,36 \pm 0,19$. Este valor encontra-se acima do limite crítico 6,2, estabelecido por Ørskov (1988) para o crescimento de bactérias celulolíticas, indicativo da manutenção de boas condições do ambiente ruminal para eficiente processo fermentativo.

A concentração média de nitrogênio amoniacal $\left(\mathrm{N}-\mathrm{NH}_{3}\right)$ no líquido ruminal coletado antes da primeira refeição, por ocasião das incubações nos tempos 3, 24 e $72 \mathrm{~h}$, foi $8,40 \pm 3,74 \mathrm{mg} / \mathrm{dl}$, aproximada dos $10 \mathrm{mg} / \mathrm{dl}$, considerada por Van Soest (1994) como nível ótimo de amônia ruminal para síntese de aminoácidos e crescimento microbiano.

A concentração total de ácidos graxos voláteis no líquido ruminal durante o período de incubação foi $67,95 \pm 6,33 \mathrm{mMol} / 1$, dos quais 74,$4 ; 18,3 \mathrm{e}$ $7,3 \%$ foram representados por acetato, propionato e butirato, respectivamente, verificando-se uma relação acetato:propionato 4,5 .

A vagem de faveira apresentou $10,8 \%$ de tanino total (TT) e $1,8 \%$ de tanino condensado (TC), como equivalente leucocianidina (Tab. 1). Segundo Aerts et al. (1999), quantidades moderadas de proantocianidinas ( 2 a $4 \%$ na MS) na forragem podem exercer efeito benéfico sobre o metabolismo protéico em ovinos, ao reduzir sua degradação no rúmen e aumentar a passagem aos intestinos, propiciando maior absorção intestinal de aminoácidos, enquanto elevadas concentrações de proantocianidinas (6 a $12 \%$ na MS) deprimem o consumo de alimento, a eficiência digestiva e a produtividade animal.
A MS da vagem de faveira, nos tamanhos de partícula 2 e $5 \mathrm{~mm}$, apresentou-se muito solúvel (fração $a=69,6 \%$ ) e pouco degradável in situ (fração $b=24,7 \%$ ). No entanto, as estimativas médias de degradação potencial da MS às taxas de passagem de 2,5 e $8 \% / h$, de $85,5,80,0$ e $77,3 \%$, respectivamente, indicam elevada degradação efetiva da MS (Tab. 3). Resultados obtidos por Batista et al. (2002) para MS de vagens da leguminosa arbórea algaroba (Prosopis juliflora) como coletadas ou secas a $80^{\circ} \mathrm{C}$ por $2 \mathrm{~h}$, com solubilidade de 54,5 e $49,0 \%$ e degradação da MS de 16,5 e $24,1 \%$, respectivamente, sugerem que o elevado teor de carboidratos não fibrosos presente na vagem de faveira resulta em elevada solubilidade, independente do tamanho da partícula, à semelhança do que ocorre com a vagem de algaroba, com elevado teor de carboidratos solúveis, que ao apresentar elevado teor de carboidratos não fibrosos, em elevada solubilidade destes $(a)$ independe do tamanho de partícula.

A elevada solubilidade das vagens de faveira em partículas de $5 \mathrm{~mm}$ torna improvável o maior efeito do escape de partículas, sendo mais justificável a elevada solubilidade decorrente do teor de CNF. No entanto, segundo MichaletDoreau e Ould-Bah (1992), o fato de as partículas que escapam à degradação serem degradadas em igual taxa que o alimento remanescente no saco, levaria à superestimativa da degradabilidade, tão maior quanto maior a fração $a$ e menor a degradação do alimento remanescente no saco.

A elevada solubilidade e a DE da vagem de faveira a $5 \% / \mathrm{h}$ para $\mathrm{MS}, 69,6$ e $80,0 \%$, e $\mathrm{PB}$, 49,9 e 68,9\%, respectivamente, indicam elevada PRDR, segundo o Agricultural... (1993). Estes resultados são compatíveis com os obtidos por Loyola et al. (1999) para o farelo de canola tratado com $15 \%$ de tanino de acácia negra ( $A$. mearnsii), em que $60,1 \%$ da MS e $63,7 \%$ da $\mathrm{PB}$ representam a fração $a$, com DE da MS e da $\mathrm{PB}$ de 75,1 e $82,6 \%$, respectivamente, à taxa de passagem de $5 \% / \mathrm{h}$. A maior degradação da MS em relação à $\mathrm{PB}$ pode ser atribuída ao efeito deletério dos compostos polifenólicos sobre a degradabilidade da $\mathrm{PB}$, o que também foi constatado por Lukhele e Van Ryssen (2003), para Colophospermum mopane e espécies do gênero Combretum do sudeste africano. 
Tabela 3. Médias das estimativas de degradação ruminal do feno de capim-Tifton 85 (Cynodon spp.) moído em partículas de $2 \mathrm{~mm}$ e de vagens de faveira (Parkia platycephala Benth.) em partículas de 2 e $5 \mathrm{~mm}$

\begin{tabular}{|c|c|c|c|}
\hline \multirow{2}{*}{ Estimativa } & \multirow[t]{2}{*}{ Feno de capim-Tifton 85} & \multicolumn{2}{|c|}{ Vagens de faveira } \\
\hline & & $2 \mathrm{~mm}$ & $5 \mathrm{~mm}$ \\
\hline \multicolumn{4}{|l|}{ Matéria seca } \\
\hline Fração solúvel ( $a, \%$ da MS) & 14,72 & 70,33 & 68,79 \\
\hline Fração insolúvel potencialmente degradável ( $b, \% \mathrm{MS})$ & 63,20 & 23,70 & 25,62 \\
\hline Taxa de degradação $(c, \% / h)$ & 2,05 & 3,73 & 3,59 \\
\hline Degradabilidade efetiva (\% da MS) $(2 \% / h)$ & 46,71 & 85,76 & 85,24 \\
\hline$(5 \% / \mathrm{h})$ & 33,10 & 80,46 & 79,50 \\
\hline$(8 \% / h)$ & 27,61 & 77,87 & 76,73 \\
\hline \multicolumn{4}{|l|}{ Proteína bruta } \\
\hline Fração solúvel ( $a$, \% da PB) & 14,05 & 50,66 & 49,12 \\
\hline Fração insolúvel potencialmente degradável $(b, \% \mathrm{~PB})$ & 85,58 & 43,32 & 44,38 \\
\hline Taxa de degradação $(c, \% / h)$ & 1,18 & 3,53 & 4,12 \\
\hline Degradabilidade efetiva (\% da PB) $(2 \% / h)$ & 45,81 & 78,31 & 79,00 \\
\hline$(5 \% / \mathrm{h})$ & 30,39 & 68,59 & 69,17 \\
\hline$(8 \% / h)$ & 25,05 & 63,92 & 64,21 \\
\hline
\end{tabular}

A degradação efetiva da MS das vagens de faveira, estimada para a taxa de passagem $3 \% / \mathrm{h}$ $(83,1 \%)$, foi mais alta que a obtida por Ngwa et al. (2000) para vagens das leguminosas leucena (Leucaena leucocephala), 53,1\%, e acácias $A$. erioloba $(47,7 \%)$, A. karroo $(44,8 \%)$ e A. tortilis $(57,2 \%)$, com FDN 39,9 a 47,7\% e FDA 28,5 a $38,4 \%$. Com base em dados de Costa (1995), estima-se a relação semente:vagens de faveira em 25:75, o que resulta em tegumento rico em carboidratos não fibrosos $(68,1 \%)$ e de alta solubilidade da MS (fração $a=69,6 \%$ ), associado às reduzidas FDN $(19,7 \%)$ e FDA $(13,1 \%)$, com significativa contribuição na estimativa da degradabilidade efetiva.

O efeito da fração $a$ na degradabilidade efetiva da MS de vagens de faveira é substancial, podendo ter contribuído para suprimir o efeito de tanino sobre a degradação deste constituinte. Segundo Tolera et al. (1997), espécies arbustivas de clima tropical e temperado apresentam alta correlação negativa entre compostos fenólicos e degradabilidade potencial $(A+B)$ e fração solúvel (a), em que a correlação com a fração $a$ é acima de $87 \%$. No entanto, a taxa de degradação da fração $b$ da MS indicou estabilização do processo de degradação a partir das $72 \mathrm{~h}$ de incubação, o que se atribui ao efeito dos taninos totais $(10,8 \%$ na MS).

Embora as vagens de faveira tenham apresentado elevada degradação potencial da MS e da PB, a taxa de degradação da MS $(c=0,037)$, mostrou-se bem menor que a obtida por Batista et al. (2002) para vagens de algaroba (Prosopis juliflora) $(c=0,099)$. Segundo Lukhele e Van Ryssen (2003), a técnica de sacos de náilon para degradação ruminal pode não ser apropriada à avaliação de alimentos com fatores antinutritivos, provavelmente devido à ligação física de polifenóis ao substrato ficar restrita ao interior do saco de náilon, que resulta em diluição da toxidade aos microrganismos, ou da ligação a suas enzimas, o que não ocorre na técnica de produção de gás in vitro.

Além da superestimativa da degradabilidade para alimentos com elevado escape de partículas (fração $a$ ), preconizada por Michalet-Doreau e Ould-Bah (1992), devido a fração $b$ ser lentamente degradada, destaca-se ainda a elevada solubilidade dos princípios nutritivos das vagens de faveira, capaz de mascarar possíveis efeitos deletérios do tanino sobre a degradação in situ, como destacado por Molina et al. (2003).

\section{CONCLUSÕES}

A degradação potencial da matéria seca, em torno de $80 \%$, indica grande possibilidade de inclusão desse concentrado energético, 19,7\% de FDN e $72,51 \%$ de NDT, em dietas suplementares para ruminantes. Apesar de a vagem de faveira ter apresentado $10,8 \%$ de taninos totais, como equivalente ácido tânico, esse princípio antinutritivo não se mostrou depressor da degradabilidade in situ da proteína. Devido à ocorrência de compostos fenólicos nas vagens de faveira, é necessária a avaliação de técnicas mais sensíveis ao efeito desses compostos sobre a taxa de degradação dos princípios nutritivos, quando da substituição do método in vivo, como é o caso da técnica de produção de gás in vitro. 


\section{REFERÊNCIAS BIBLIOGRÁFICAS}

AERTS, R.J.; BARRY, T.N.; McNABB, W.C. Polyphenols and agriculture: beneficial effects of proanthocyanidins in forages. Agric. Ecosyst. Environ., v.75, p.1-12, 1999.

AGRICULTURAL and Food Research Council (AFRC). Energy and protein requirements of ruminants. Wallingford, UK: CAB International, 1993. 159 p.

ALVES, A.A.; SALES, R.O; NEIVA, J.N.M. Energetic value of faveira (Parkia platycephala Benth.) pods for ruminants. In: WORLD CONGRESS OF ANIMAL PRODUCTION, 9., 2003, Porto Alegre. Anais... Porto Alegre: ALPA, 2003. 1CD. (Resumo expandido).

ANDRADE, P. Técnica in situ (saco de náilon) na avaliação de alimentos para ruminantes. In: REUNIÃO ANUAL DA SOCIEDADE BRASILEIRA DE ZOOTECNIA, 31.; SIMPÓSIO INTERNACIONAL DE PRODUÇÃO DE RUMINANTES, 1994, Maringá. Anais... Maringá: SBZ/EDUEM, 1994. p.141-147.

BATISTA, A.M.; MUSTAFA, A.F.; McKINNON, J.J. et al. In situ ruminal and intestinal nutrient digestibilities of mesquite (Prosopis juliflora) pods. Anim. Feed Sci. Technol., v.100, p.107-112, 2002.

CAMPOS, J. Tabelas para cálculo de rações. 2.ed. Viçosa: UFV, 1995. 64p.

CARVALHO, J.H.; RAMOS, G.M. Produtividade da faveira (Parkia platycephala Benth.) em três municípios piauienses. In: CONGRESSO BRASILEIRO DE FORRAGEIRAS E PASTAGENS NATIVAS, 1983, Olinda. Anais... Recife: IPA, 1983. p.44. (Resumo).

COSTA, M.R. Efeito de tratamentos prégerminativos na germinação e produção de mudas de visgueiro (Parkia platycephala Benth.). 1995. 9f. Monografia (Graduação em Engenharia Agronômica) - Centro de Ciências Agrárias, Universidade Federal da Paraíba, Areia.

HALL, M.B. Neutral detergent-soluble carbohydrates nutritional relevance and analysis: a laboratory manual. Gainesville; FL: University of Florida, Institute of Food and Agricultural Sciences, 2000. 76p. (Bulletin n. 339).
LOYOLA, V.R.; SANTOS, G.T.; ZEOULA, L.M. et al. Degradabilidade in situ do farelo de canola tratado com calor e/ou tanino. Rev. Bras. Zootec., v.28, p.598-604, 1999.

LUKHELE, M.S., VAN RYSSEN, J.B.J. The chemical composition and potential nutritive value of the foliage of four subtropical tree species in southern Africa for ruminants. S. Afric. J. Anim. Sci., v.33, p.132-141, 2003.

MAKKAR, H.P.S. Recommendation for quality control of in sacco nylon bag technique. In: FIRST RESEARCH COORDINATION MEETING OF THE FAO/IAEA COORDINATED RESEARCH PROJECT FOOD AND AGRICULTURE ORGANIZATION OF THE UNITED NATIONS FOR USE OF NUCLEAR AND RELATED TECHNIQUES TO DEVELOP SIMPLE TANNIN ASSAYS FOR PREDICTING AND IMPROVING THE SAFETY AND EFFICIENCY OF FEEDING RUMINANTS ON TANNINIFEROUS TREE, 1999, Viena. Proceedings... Viena: FAO/IAEA, 1999. 3p.

MATHEW, S.; SAGATHEVAN, S.; THOMAS, J. et al. An HPLC method for estimation of volatile fatty acids in ruminal fluid. Indian $J$. Anim. Sci., v.67, p.805-807, 1997.

MICHALET-DOREAU, B.; OULD-BAH, M.Y. In vitro and in sacco methods for the estimation of dietary nitrogen degradability in the rumen: a review. Anim. Feed Sci. Technol., v.40, p.57-86, 1992.

MOLINA, L.R.; RODRIGUEZ, N.M.; SOUSA, B.M. et al. Parâmetros de degradabilidade potencial da matéria seca e da proteína bruta das silagens de seis genótipos de sorgo (Sorghum bicolor (L.) Moench), com e sem tanino no grão, avaliados pela técnica in situ. Rev. Bras. Zootec., v.32, p.222-228, 2003.

NASCIMENTO, M.P.S.C.B.; OLIVEIRA, M.E.A.; NASCIMENTO, H.T.S. et al. Forrageiras da Bacia do Parnaíba: usos e composição química. Teresina: EMBRAPACPAMN/Recife: Associação Plantas do Nordeste - PNE, 1996. 86p. (EMBRAPA-CPAMN. Documentos, 19).

NGWA, A.T.; NSAHLAI, I.V.; BONSI, M.L.K. The potential of legume pods as supplements to 
low quality roughages. S. Afric. J. Anim. Sci., v.30, Suppl. 1, p.107-108, 2000.

NOCEK, J.E. In situ e outros métodos para estimar a proteína ruminal e a digestibilidade da energia: uma revisão. In: SIMPÓSIO INTERNACIONAL DE DIGESTIBILIDADE EM RUMINANTES, Lavras, 1997. Anais... Lavras: UFLA-FAEPE, 1997. p.240-285.

NOZELLA, E.F. Determinação de taninos em plantas com potencial forrageiro para ruminantes. 2001. 58f. Dissertação (Mestrado) Centro de Energia Nuclear na Agricultura, Universidade de São Paulo, Piracicaba, SP.

NUTRIENT requirements of dairy cattle. 7.ed. Washington, D.C.: National Academy, 2001. $381 \mathrm{p}$.

NUTRIENT requirements of sheep. 6.ed. Washington, D.C.: National Academy, 1985. 99p.

OFFICIAL methods of analysis. 15.ed. Arlington, VA: AOAC, 1990.

ØRSKOV, E.R. Nutrición proteica de los rumiantes. Zaragoza, España: Acribia, 1988. $178 \mathrm{p}$.

ØRSKOV, E.R.; McDONALD, I. The estimation of protein degradability in the rumen from incubation measurements weighted according to rate of passage. J. Agric. Sci., v.92, p.499-503, 1979.

QUANTIFICATION of tannins in tree foliage: a laboratory manual for the FAO/IAEA coordinated research project on 'use of nuclear and related techniques to develop simple tannin assays for predicting and improving the safety and efficiency of feeding ruminants on tanniniferous tree foliage'. Viena: FAO/IAEA, 2000. 26p. (Working Document).

SAMPAIO, I.B.M. Contribuições estatísticas e de técnica experimental para ensaios de degradabilidade de forragens quando avaliada in situ. In: REUNIÃO ANUAL DA SOCIEDADE BRASILEIRA DE ZOOTECNIA, 31.; SIMPÓSIO INTERNACIONAL DE PRODUÇÃO DE RUMINANTES, Maringá, 1994. Anais... Maringá: SBZ/EDUEM, 1994. p.81-88.

SAMPAIO, I.B.M.; PIKE, D.J.; OWEN, E. Optimal design for studying dry matter degradation in the rumen. Arq. Bras. Med. Vet. Zootec., v.47, p.373-383, 1995.

SNIFFEN, C.J.; O'CONNOR, J.D.; VAN SOEST, P.J. et al. A net carbohydrate and protein system for evaluating cattle diets: II. Carbohydrate and protein availability. J. Anim. Sci., v.70, p.3562-3577, 1992.

TOLERA, A.; KHAZAAL, K.; ØRSKOV, E.R. Nutritive evaluation of some browse species. Anim. Feed Sci. Technol., v.67, p.181-195, 1997.

USER'S guide: statistics. Cary, NC: SAS Institute, 2000.

VAN SOEST, P.J. Nutritional ecology of the ruminant. 2.ed. New York: Cornell University, 1994. 476p.

VAN SOEST, P.J.; ROBERTSON, J.B.; LEWIS, B.A. Methods for dietary fiber, neutral detergent fiber, and nonstarch polysaccharides in relation to animal nutrition. J. Dairy Sci., v.74, p.35833597, 1991.

VIEIRA, P.F. Efeito do formaldeido na proteção de proteínas e lipídeos em rações para ruminantes. 1980. 98f. Tese (Doutorado) Universidade Federal de Viçosa, Viçosa, MG.

WEISS, W.P.; CONRAD, H.R.; PIERRE, N.R.S. A theoretically-based model for predicting total digestible nutrient values of forages and concentrates. Anim. Feed Sci. Technol., v.39, p.95-110, 1992. 